\title{
Effect of a Small Addition of Transition Elements on Annealing Characteristics of Cold-Worked Pure Copper
}

\author{
By Hisashi Suzuki* and Motohiro Kanno*
}

\begin{abstract}
The effects of a single addition of transition elements such as $\mathrm{Ti}, \mathrm{Zr}, \mathrm{Hf}, \mathrm{V}, \mathrm{Cr}, \mathrm{Mn}$ and $\mathrm{Fe}$ on annealing characteristics of cold-worked commercially available pure copper were studied with addition amounts up to $1000 \mathrm{~mol} \mathrm{ppm}$.

The recrystallization of cold-worked pure copper was enhanced by a trace addition of each element. To improve the heat-resistance of pure copper, the addition of $\mathrm{Zr}$ or $\mathrm{Hf}$ was most effective, and the addition amount of only $170 \mathrm{~mol}$ ppm was sufficient for the effect. The enhancement of recrystallization was studied in detail, and as a result it was proved to be due to the fact that the addition elements formed sulfides reducing the amount of impurity of sulfur dissolved in the pure copper. The stored energy of cold-worked pure copper was considered not to be increased by the trace additions. Additionally, annealing treatment before cold-working was shown to be effective for the enhancement of recrystallization.
\end{abstract}

(Received June 12, 1984)

Keywords: pure copper, transition element, trace addition, annealing, recrystallization, enhancement of recrystallization, heat-resistance, impurity of sulfur, sulfide, cold-working

\section{Introduction}

It is widely known ${ }^{(1)-(4)}$ that the recrystallization temperature or the half-softening temperature of cold-worked pure copper is influenced by the addition of foreign elements. However, the effects of small additions less than about $1000 \mathrm{~mol} \mathrm{ppm}$ were not fully described. Consequently, studies on this subject were carried out by the present authors on additives belonging to group $^{(5)} \mathrm{IIIb}$ to $\mathrm{VIb}$, transition ${ }^{(6)(7)}$ and IIIa group elements ${ }^{(8)}$. In the present paper, the effects of addition of transition elements are described.

\section{Experimental}

Standard pure copper ingot (named $\mathrm{Cu}(1)$ ) and copper ingots with the single addition of $\mathrm{Ti}, \mathrm{Zr}, \mathrm{Hf}, \mathrm{V}, \mathrm{Cr}, \mathrm{Mn}$ or $\mathrm{Fe}$ in amounts up to about $1000 \mathrm{~mol} \mathrm{ppm}$ were prepared by vacuum melting and casting, using commercially

* This paper is a summary of papers originally published in Japanese in J. Japan Inst. Metals, 48 (1984), 209, and Tetsu-to-Hagané, 70 (1984), 1977.

** Department of Metallurgy and Materials Science, Faculty of Engineering, The University of Tokyo , Tokyo 113, Japan. available electrolytic copper (99.996 mass\% purity) and addition metals ( 99.9 mass \% purity).

The oxygen content of each ingot was kept constant at about $8 \mathrm{~mol} \mathrm{ppm}$. Each ingot was homogenized at $1073 \mathrm{~K}$ for $74 \mathrm{ks}$, quenched, scalped and subsequently cold-rolled to a plate $4 \mathrm{~mm}$ thick. A part of the plate was successively cold-rolled to a sheet $1 \mathrm{~mm}$ thick (total reduction, $94 \%$ ) to obtain specimens for hardness measurements and structural observations. Another part of the plate was cut into bars having a cross section of $4 \mathrm{~mm} \times 4 \mathrm{~mm}$, rounded by use of a file, cold-drawn into a wire $2.5 \mathrm{~mm}$ in dia., vaccum-annealed at 1073 $\mathrm{K}$ for $3.6 \mathrm{ks}$, quenched and subsequently colddrawn to a wire $0.5 \mathrm{~mm}$ in dia. (reduction of area, about $96 \%$ ). The wire specimens were used for electrical resistivity measurements.

Cold-worked sheet and wire specimens were stored in dry ice to prevent any structural changes after cold-working. The sheet specimens were subjected to isochronal annealing at temperatures ranging from 300 to $800 \mathrm{~K}$ mainly for $1.8 \mathrm{ks}$, and the wire specimens to isothermal annealing at $423 \mathrm{~K}$. Annealing below $473 \mathrm{~K}$ was performed in an oil bath; above $473 \mathrm{~K}$, in a salt bath. For the specimens cold-worked or heat-treated, hardness measure- 
ments at room temperature (load, $4.9 \mathrm{~N}$; loading time, $45 \mathrm{~s}$ ) and electrical resistivity measuremens at $77 \mathrm{~K}$ were made. Structural observations by use of optical microscope, SEM and TEM were also made.

In the course of the above experiments, it was found that recrystallization of cold-worked pure copper (pure copper specimen is called $\mathrm{Cu}(1)$ specimen) was enhanced to a great extent by the trace addition of each element. Then, the following wire specimens were prepared in approximately the same way as previously mentioned to obtain supplementary specimens to elucidate the phenomenon: (a) Specimens which were made by adding $\mathrm{Ti}, \mathrm{Zr}$ or $\mathrm{V}$ within about $30 \mathrm{~mol} \mathrm{ppm}$ to $\mathrm{Cu}(1)$ (called $\mathrm{Cu}$ (1)-base specimens); (b) two-types of pure copper specimens which were made by using the electrolytic coppers obtained by re-electrolyzing the commercially available electrolytic copper in $\mathrm{H}_{2} \mathrm{SO}_{4}-\mathrm{CuSO}_{4}$ and $\mathrm{HNO}_{3}-$ $\mathrm{Cu}\left(\mathrm{NO}_{3}\right)_{2}$ solutions, respectively (named $\mathrm{Cu}(2)$ and $\mathrm{Cu}(3)$ specimens, respectively); and (c) specimens which were made by adding a certain amount of sulfur, or sulfur together with $\mathrm{Ti}, \mathrm{Zr}$ or $\mathrm{V}$ to $\mathrm{Cu}(3)(\mathrm{Cu}(3)$-base specimens). In preparing specimens (a), (b) and (c), homogenization at $1073 \mathrm{~K}$ was omitted, because the addition amount was extremely small. Wire specimens $(0.5 \mathrm{~mm}$ in dia., $99 \%$ reduction) were used for the measurements of electrical resistivity changes during isothermal annealing at $423 \mathrm{~K}$. As dispersed particles were found to exist in cast structures, analyses by means of energy dispersive X-ray spectroscopy (EDS) were employed on those particles.

\section{Experimental Results}

Figure 1 shows hardness changes due to isochronal annealing for the specimens containing $\mathrm{Ti}, \mathrm{Zr}$ and $\mathrm{V}$. It is clear that the half-softening temperature $\left(T_{\mathrm{H}}\right)$ of $\mathrm{Cu}(1)$ specimen is regularly decreased by the trace addition of each element. The decrease in $T_{\mathrm{H}}$ is most marked in specimens with the addition ${ }^{\dagger}$ of $13 \mathrm{~mol}$ ppm Ti, $21 \mathrm{~mol} \mathrm{ppm} \mathrm{Zr}$ or $16 \mathrm{~mol} \mathrm{ppm} \mathrm{V} \mathrm{(call-}$ ed $\mathrm{Ti}-13, \mathrm{Zr}-21$ or $\mathrm{V}-16$ specimen), and the maximum decrease is about $65 \mathrm{~K}$ for $\mathrm{V}-16$ specimen $\left(T_{\mathrm{H}}\right.$ of $\mathrm{Cu}(1)$ was about $\left.435 \mathrm{~K}\right)$. Con- versely, in $\mathrm{Ti}$ - and $\mathrm{Zr}$-added specimens, a sharp rise in $T_{\mathrm{H}}$ is observed with increasing amount. The Ti-610 and $\mathrm{Zr}-175$ specimens show a value of $T_{\mathrm{H}}$ as high as about 700 and $820 \mathrm{~K}$, respectively. In V-added specimens, the $T_{\mathrm{H}}$ is always lower than that of $\mathrm{Cu}(1)$ specimen within the amount up to about $400 \mathrm{~mol} \mathrm{ppm}$.

The $T_{\mathrm{H}}$ values obtained from isochronal annealing curves are summarized for seven types of additives in Fig. 2, as a function of the addi-

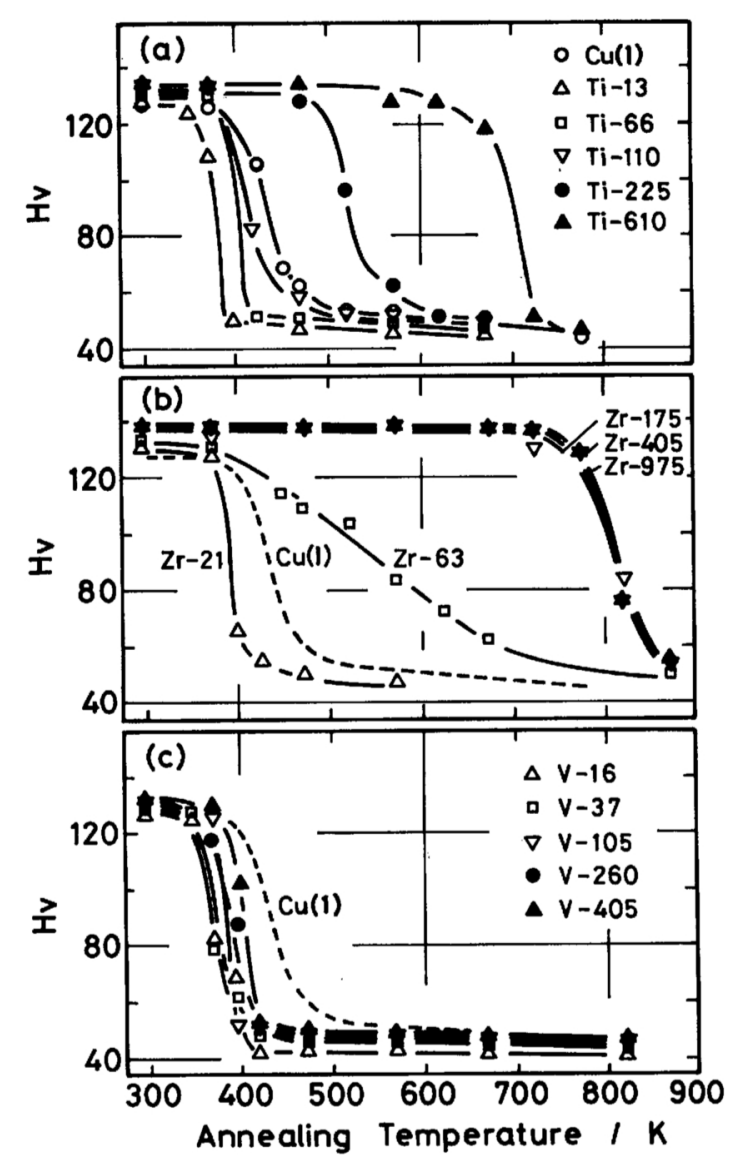

Fig. 1 Hardness (Hv) vs. annealing temperature curves of cold-worked copper specimens with the addition of $\mathrm{Ti}, \mathrm{Zr}$ or $\mathrm{V}$. Numerals show the addition amounts in mol ppm. The result of $\mathrm{Cu}(1)$ specimen is also shown. Annealing time, $1.8 \mathrm{ks}$.

$\dagger$ The addition amounts were analytical values by ICP spectroscopy. This is in common in the following. The accuracy of analytical values is within $\pm 5 \%$ for the amounts less than several tens $\mathrm{mol} \mathrm{ppm}$ and $\pm 2 \%$, for the amounts less than several hundreds mol ppm. 
Effect of a Small Addition of Transition Elements on Annealing Characteristics of Cold-Worked Pure Copper 71

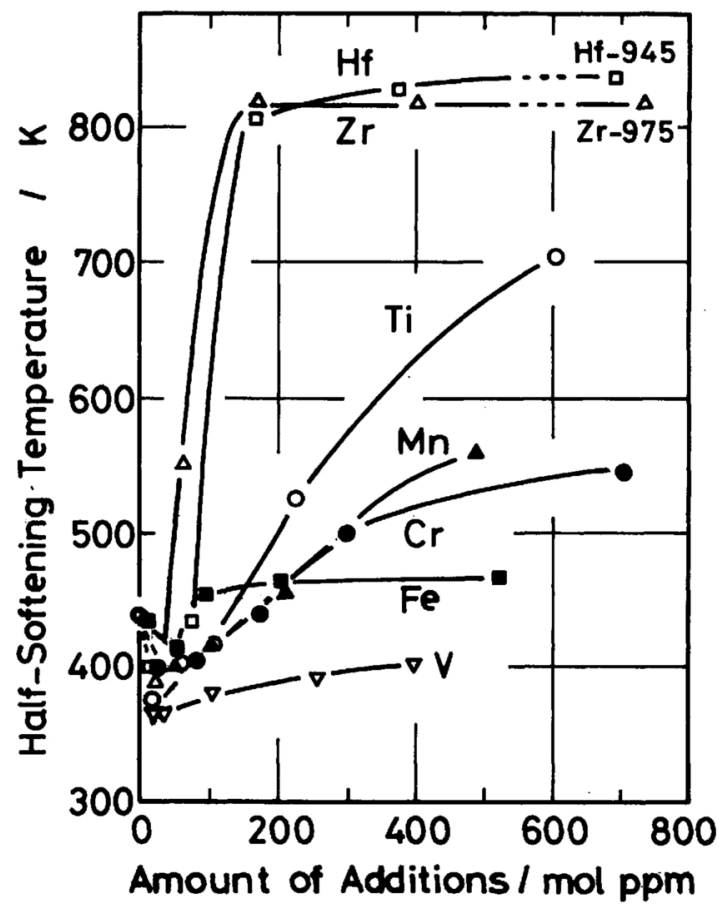

Fig. 2 Half-softening temperature of cold-worked specimens as a function of addition amount. Refer to Fig. 1.
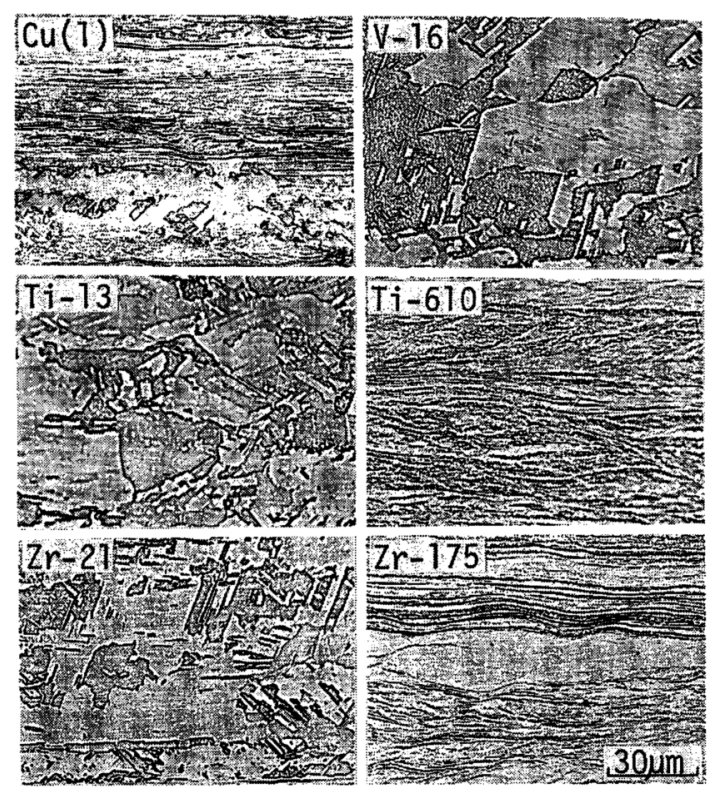

Fig. 3 Optical micrographs of cold-worked specimens annealed at $423 \mathrm{~K}$ for $1.8 \mathrm{ks}$. It is shown that Ti-13, $\mathrm{Zr}-21$ and V-16 specimens easily recrystallize in contrast to Ti610 and Zr-175 specimens. Refer to Fig. 2. tion amount. It is noted that a trace addition of all the elements lowers the $T_{\mathrm{H}}$ of $\mathrm{Cu}(1)$ specimen. The $T_{\mathrm{H}}$ appears to show a minimum for the additions of about $30 \mathrm{~mol} \mathrm{ppm}$ or below. When the addition amounts exceed about $30 \mathrm{~mol} \mathrm{ppm}$, the $T_{\mathrm{H}}$ rises for each element with increasing amount. The increase in $T_{\mathrm{H}}$ is marked for the addition of $\mathrm{Zr}$ or $\mathrm{Hf}$, and it is very slight for $\mathrm{V}$ addition. It is also noted that $\mathrm{Zr}$ or $\mathrm{Hf}$ addition as small as about 170 mol ppm is effective for a sharp increase in $T_{\mathrm{H}}$. When the annealing time was prolonged from $1.8 \mathrm{ks}$ to $3.6 \mathrm{ks}$, the $T_{\mathrm{H}}$ of each specimen slightly decreased; however, the tendency of the curves in Fig. 2 was maintained. An example of optical micrographs of specimens annealed at $423 \mathrm{~K}$ for $1.8 \mathrm{ks}$ is shown in Fig. 3. The structures developed in the specimens were as expected (see Fig. 2).

Figure 4 illustrates the electrical resistivity of

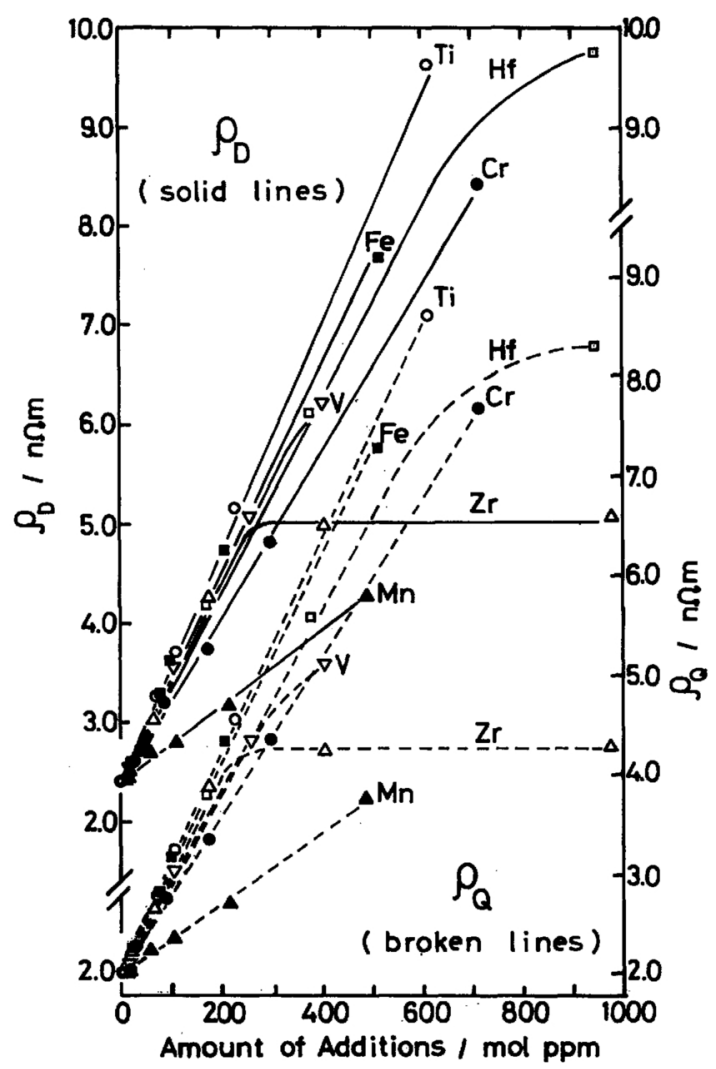

Fig. 4 Electrical resistivity of specimens as a function of addition amount. $\rho_{\mathrm{D}}$ : cold-drawn state (reduction, $96 \%), \rho_{\mathrm{Q}}$ : annealed state. 
specimens in the cold-drawn state $\left(\rho_{\mathrm{D}}\right)$ and in the quenched state after annealing of the colddrawn wire at $1073 \mathrm{~K}$ for $1.8 \mathrm{ks}\left(\rho_{\mathrm{Q}}\right)$, as a function of the addition amount. The value of $\rho_{D}$ and $\rho_{\mathrm{Q}}$ of each specimen increase linearly with increasing amount. In the case of $\mathrm{Zr}, \mathrm{V}$ and $\mathrm{Hf}$ additions, however, both curves deviate from the straight line, when the amount is over about 200,300 and $600 \mathrm{~mol}$ ppm, respectively. This can be explained in view of the fact that these limiting values are nearly coincident with the solid solubilities ${ }^{(9)(10)}$ of the elements in copper at $1073 \mathrm{~K}$.

At first, annealing experiments were carried out for $\mathrm{Zr}-175$ and $\mathrm{Hf}-170$ specimens, because they had extremely high softening temperature or high heat-resistance (refer to Fig. 2), on the other hand, they had high electrical resistivities. Results obtained are as follows. The resistivity of $\mathrm{Zr}-175$ specimen lowered to the value of $3.24 \mathrm{n} \Omega \mathrm{m}(18.06 \mathrm{n} \Omega \mathrm{m}$ and about $95 \%$ IACS at $293 \mathrm{~K}$ ) after isothermal annealing at $573 \mathrm{~K}$ (being lower than $T_{\mathrm{H}}$ of this specimen) for $144 \mathrm{ks}$. However, the $T_{\mathrm{H}}$ was not affected by this heat-treatment. Nearly the same results were also obtained for the $\mathrm{Hf}-170$ specimen. The precipitation of $\mathrm{Cu}_{3} \mathrm{Zr}^{(11)}$ or $\mathrm{Cu}_{7} \mathrm{Hf}_{2}{ }^{(12)}$ during annealing is considered to be responsible for these results. In fact, the precipitates were observed on dislocation lines in TEM micrographs as shown in Fig. 5. It is very interesting that copper-base materials having a high heat-resistance and high electrical conductivity are obtainable by the addition of $\mathrm{Zr}$ (or Hf) of only about $170 \mathrm{~mol}$ ppm to the pure copper, because the value of $170 \mathrm{~mol} \mathrm{ppm}$ is in contrast to $1000 \mathrm{~mol} \mathrm{ppm} \mathrm{(0.15} \mathrm{mass \% )} \mathrm{in} \mathrm{a} \mathrm{com-}$

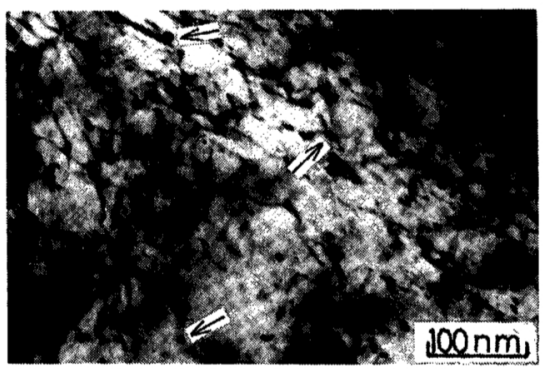

Fig. 5 Precipitate structure of $\mathrm{Zr}-175$ specimen, coldworked and then aged at $823 \mathrm{~K}$ for $1.8 \mathrm{ks}$. Arrows show precipitates of $\mathrm{Cu}_{3} \mathrm{Zr}$ on dislocation lines. mercially available $\mathrm{Cu}-\mathrm{Zr}$ alloy.

Next, the enhancement of recrystallization in cold-worked pure copper having trace additions was studied in detail using supplementary specimens. Resistivity changes during annealing at $423 \mathrm{~K}$ were first examined on cold-worked $\mathrm{Cu}(1)$ and $\mathrm{Cu}(1)$-base specimens. The results are shown in Figs. 6 and 7. It is clearly shown that the rate of resistivity change of $\mathrm{Ti}-7$ specimen is greatest in the Ti-added specimens, and that of the $\mathrm{Zr}-5$ specimen, in the $\mathrm{Zr}$-added specimens. In V-added specimens, the V-10 specimen showed the most enhanced recrystallization. These results indicate that recrystallization is most accelerated, when the addition amount is about $10 \mathrm{~mol} \mathrm{ppm} \mathrm{or}$

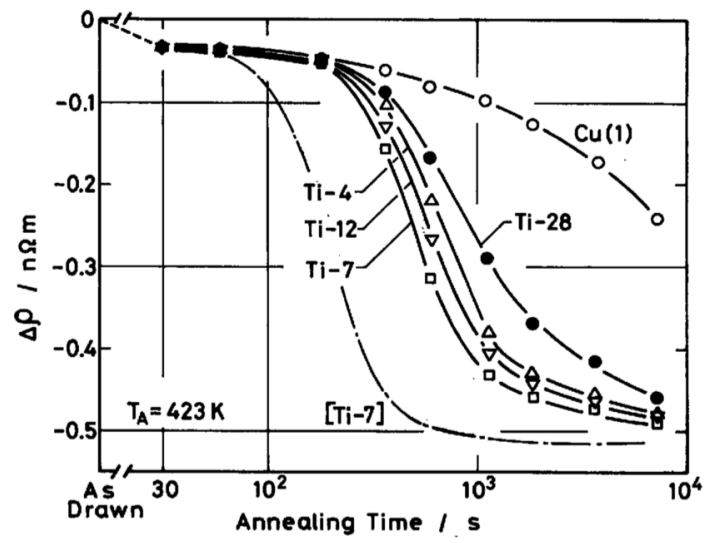

Fig. 6 Electrical resistivity change $(\Delta \rho)$ vs. annealing time curves of cold-worked specimens with $\mathrm{Ti}$.

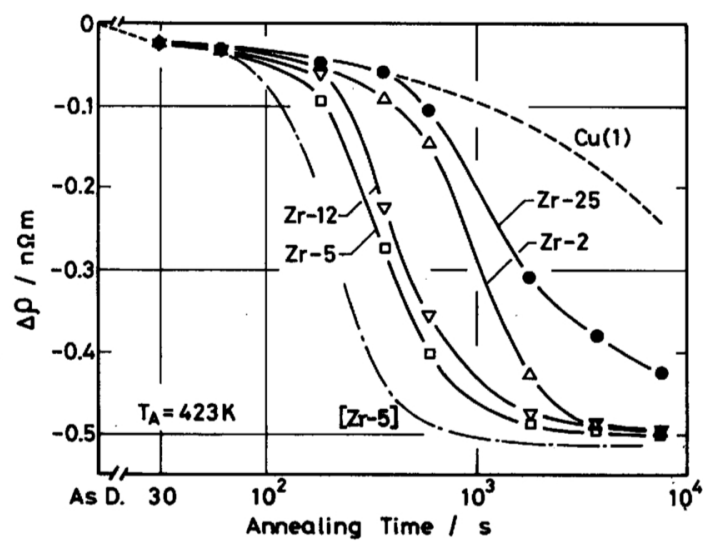

Fig. 7 The $\Delta \rho$ vs. annealing time curves of cold-worked specimens with Zr. Refer to Fig. 6. 
below, the value being lower than those shown in Fig. 1 or 2.

Figure 8 illustrates the values of $\rho_{\mathrm{D}}$ and $\rho_{\mathrm{Q}}$ of $\mathrm{Ti}-, \mathrm{Zr}$ - or $\mathrm{V}$-added specimens as a function of the addition amount. It is seen that both values of $\mathrm{Cu}(1)$ specimen are almost unchanged by the additions up to several mol ppm. This result suggests that each additive should interact with a certain impurity in the pure copper and that the interaction relates to the enhancement of the recrystallization.

The rate of recrystallization of cold-woked $\mathrm{Cu}(2)$ and $\mathrm{Cu}(3)$ specimens was studied in comparison with that of $\mathrm{Cu}(1)$. The result of resistivity measurements is shown in Fig. 9. The recrystallization rate of $\mathrm{Cu}(2)$ is nearly the

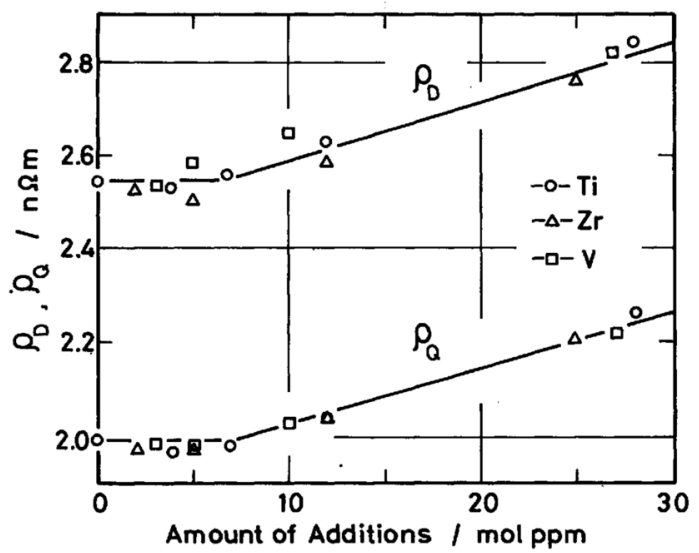

Fig. 8 Electrical resistivity of specimens as a function of addition amount. $\rho_{\mathrm{D}}$ : cold-drawn state (reduction, 99\%); $\rho_{\mathrm{Q}}$ : annealed state.

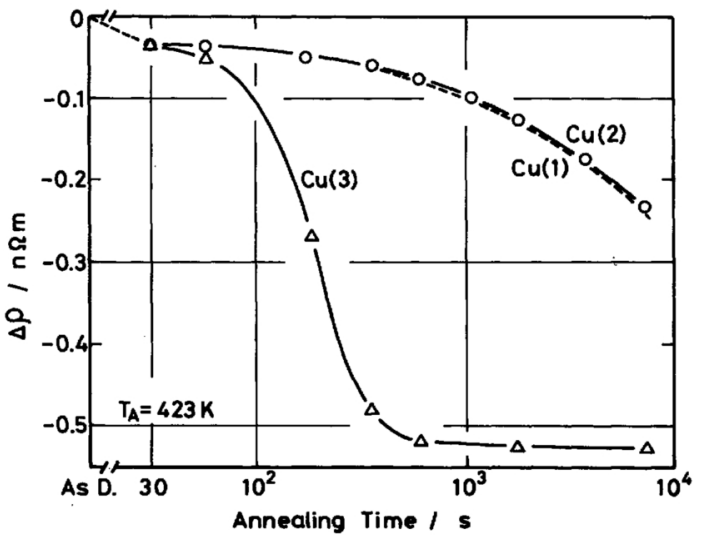

Fig. 9 The $\Delta \rho$ vs. annealing time curves of three types of cold-worked pure copper specimens. The curve of $\mathrm{Cu}(1)$ is referred to. same as that of $\mathrm{Cu}(1)$, while the rate of $\mathrm{Cu}(3)$ is extremely high. The $T_{H}$ of cold-worked $\mathrm{Cu}(3)$ was $365-370 \mathrm{~K}$. Table 1 shows the result of analyses of three types of pure coppers. It is probable that the recrystallization of coldworked pure copper is enhanced when the impurity of sulfur decreases.

In relation to this, the resistivity changes during annealing at $423 \mathrm{~K}$ were studied for $\mathrm{Cu}(3)$ base specimens. The results are shown in Fig. 10. The rate of recrystallization of $\mathrm{Cu}(3)$ decreases with increasing addition amount of sulfur, and that of S-13 specimen becomes lower than that of $\mathrm{Cu}(1)$. The rate of $\mathrm{S}-13$ specimen, however, sharply increases beyond the rate of $\mathrm{Cu}(1)$, when $41 \mathrm{~mol} \mathrm{ppm} \mathrm{Ti}$ is added to S-13 specimen. Consequently, the curve of $(\mathrm{S}-13)+(\mathrm{Ti}-41)$ specimen is situated midway between those of $\mathrm{Cu}(3)$ and $\mathrm{Cu}(1)$. The curves of $(\mathrm{S}-16)+(\mathrm{Zr}-16)$ and $(\mathrm{S}-14)+(\mathrm{V}-12)$ specimens were also situated between those of $\mathrm{Cu}(3)$ and $\mathrm{Cu}(1)$.

Then, SEM structures of (S-13)+(Ti-41), (S-

Table 1 The result of analyses of three types of pure coppers (mol ppm).

\begin{tabular}{ccccccc}
\hline & $\mathrm{Ag}$ & $\mathrm{Fe}$ & $\mathrm{S}$ & $\mathrm{Ni}$ & $\mathrm{O}$ & Others \\
\hline $\mathrm{Cu}(1)$ & 5.0 & 2.0 & 4.0 & $<1$ & 8 & $*$ \\
\hline $\mathrm{Cu}(2)$ & 2.4 & 0.6 & 4.4 & $<1$ & 8 & $*$ \\
\hline $\mathrm{Cu}(3)$ & 1.0 & 1.8 & $<1$ & $<1$ & 8 & $*$ \\
\hline
\end{tabular}

* The amount of any impurity such as P, As, Sn, Si, Al, $\mathrm{Sb}, \mathrm{Te}, \mathrm{Pb}$ and $\mathrm{Bi}$ is less than $1 \mathrm{~mol} \mathrm{ppm}$.

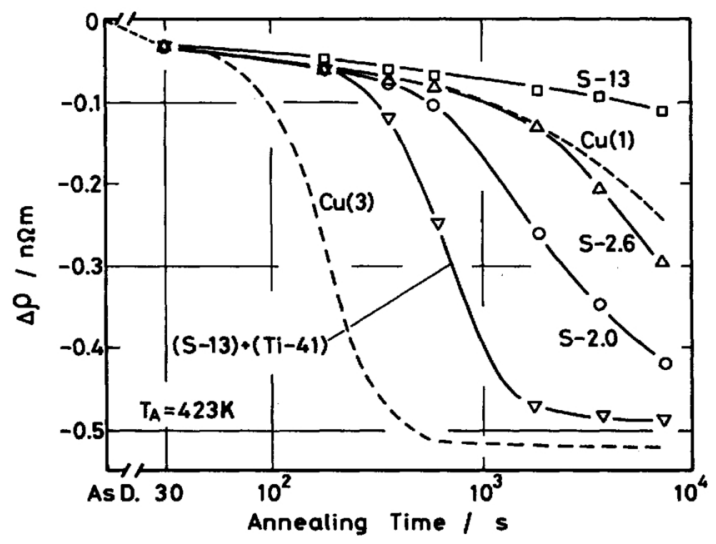

Fig. 10 The $\Delta \rho$ vs. annealing time curves of cold-worked $\mathrm{Cu}(3)$-base specimens. 
$16)+(\mathrm{Zr}-16)$ and $(\mathrm{S}-14)+(\mathrm{V}-12)$ ingots were examined with the result that fine dispersed particles of $0.2-0.3 \mu \mathrm{m}$ generally existed within the grains of cast structures. The fine dispersed particles were not observed in S-13, S-14 and S-16 ingots. An example of the dispersed particles is shown in Fig. 11 for the two types of ingots. The results of EDS analyses on the particles in each ingot are shown in Fig. 12. It is obvious that the particles are sulfides of the additive elements ${ }^{\dagger}$. The existence of dispersed sulfide particles was the same as in the coldworked specimens. Sulfide particles existed also in $\mathrm{Cu}(1)$-base specimens. These results prove that the additives undoubtedly interact with the impurity of sulfur.

The series of results described above indicates that the impurity of sulfur elevates the recrystallization temperature of commercially available pure copper, and that the addition elements interact with the impurity of sulfur to decrease the dissolved sulfur in the matrix, leading to the enhanced recrystallization of

(a)

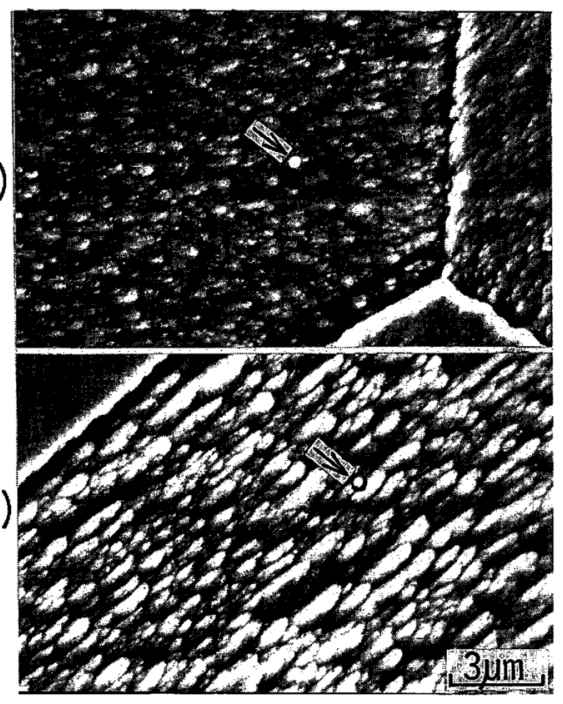

Fig. 11 SEM images of ingots of $\mathrm{Cu}(3)$-base specimens, electropolished and subsequently etched in $\mathrm{NH}_{4} \mathrm{OH}-$ $\mathrm{H}_{2} \mathrm{O}_{2}$ aqueous solution. (a) (S-13) plus (Ti-41) specimen and (b) (S-16) plus (Zr-16) specimen. An arrow shows the dispersed particles within the grain.

$\dagger$ Strictly speaking, there existed another sort of dispersed particles from which each addition element was only detected. They were thought to be oxides of the additives. commercially available pure copper.

\section{Discussion}

Among the results obtained in this study, the phenomenon that a trace addition of each transition element lowered the half-softening temperature or enhanced the recrystallization of cold-worked commercially available pure copper is considered to be of significant interest. In the experiments using the supplementary specimens with $\mathrm{Ti}, \mathrm{Zr}$ or $\mathrm{V}$, recrystallization was most enhanced when the addition amount was about $10 \mathrm{~mol} \mathrm{ppm}$ or below, and it was proved that the enhanced recrystallization was caused by the fact that the impurity of sulfur dissolved in the commercially available pure copper was reduced by the sulfide formation of the additives. Consequently, the following discussion is limited to the phenomenon that the recrystallization of cold-worked commercially available pure copper is enhanced.

According to the results of Lucci and his coworkers ${ }^{(13)}$ who studied the effects of addition elements on the recrystallization tempera-

(a)

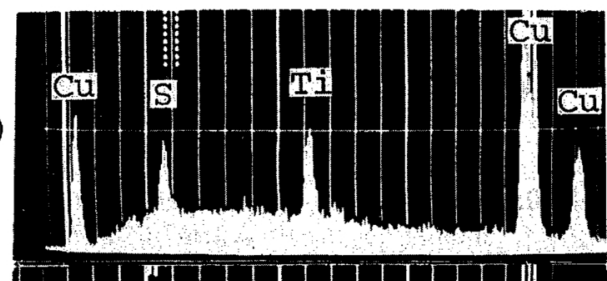

(b)

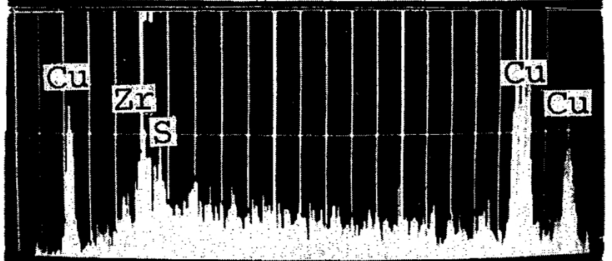

(c)

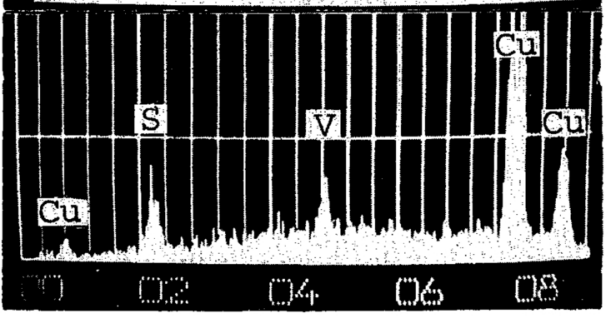

Fig. 12 The results of EDS analyses on dispersed particles appearing in ingots, (a) (S-13) plus (Ti-41), (b) (S16) plus (Zr-16) and (c) (S-14) plus (V-12). Refer to Fig. 11. 
ture and stored energy of cold-worked pure copper by means of differential scanning calorimetry, a small amount of single addition of $\mathrm{Mn}, \mathrm{Fe}, \mathrm{Ni}$, etc., increases the stored energy, resulting in a decrease in the recrystallization temperature of cold-worked pure copper by about $30-40 \mathrm{~K}$. Similar results were reported by Haessner and his coworkers ${ }^{(14)}$ on the cold-worked copper-single-crystals which were doped with $\mathrm{Co}, \mathrm{Ni}, \mathrm{Fe}, \mathrm{Zr}$, etc.

On the other hand, Williams ${ }^{(15)}$ pointed out prior to the above papers that the energy release due to recrystallization was smaller than that of the real stored energy, because energy loss occurred during recovery at temperatures below the recrystallization temperature. This means that the stored energy estimated from the energy release at the recrystallization temperature is an apparent one, and that it tends to be smaller in pure copper than in the specimens having a lower recrystallization temperature as compared with that of pure copper, even in a case in which the real stored energy of pure copper is identical with that of specimens. Now, referring to the results of Figs. 4 and 8 , the value of $\left(\rho_{\mathrm{D}}-\rho_{\mathrm{Q}}\right)$ of pure copper does not change, when the addition amounts are up to about $100 \mathrm{~mol} \mathrm{ppm}$. This suggests that the stored energy of pure copper is not increased by a small addition of foreign elements.

Aside from the discussion on stored energy, the enhancement of recrystallization observed in the specimens was proved to be due to the desulfurization effect of the additives. In other words, it was clarified that the recrystallization of commercially available pure copper is largely checked by a trace amount of impurity of sulfur. This result accords well with the result of Coutsouradis et al.$^{(16)}$ that a sulfur addition of 6 and $12 \mathrm{~mol} \mathrm{ppm} \mathrm{raised} \mathrm{the} \mathrm{recrystalliza-}$ tion temperature of cold-worked pure copper by about 20 and $60 \mathrm{~K}$, respectively.

The effect of impurities other than sulfur on the recrystallization temperature is next considered. With respect to the effect of oxygen, Bigelow and $\mathrm{Chen}^{(17)}$ reported that an oxygen content of about $1400 \mathrm{~mol} \mathrm{ppm}$ raised the recrystallization temperature of cold-worked pure copper by only several degrees $\mathrm{K}$. In this connection, it was confirmed in this study that, under a fixed oxygen content of $8 \mathrm{~mol} \mathrm{ppm}$, the rate of recrystallization of pure copper was sharply influenced by a small variation in sulfur content as shown in Figs. 9 and 10 . Therefore, it can be said that the impurity of oxygen has virtually no relation to the recrystallization temperature of pure copper. In regards to the effects of $\mathrm{Ag}$ and $\mathrm{Fe}$, it is likely that trace impurities of $\mathrm{Ag}$ and Fe hardly affect their recrystallization temperature based on the result of Fig. 9.

Next, the sulfide formation of additives is considered. According to thermodynamic data, ${ }^{(18)(19)}$ the standard formation energies of titanium, zirconium sulfides, etc., are negative, and their absolute values are much lager than those of copper sulfides (no available data for vanadium sulfides were found). Therefore, there is no doubt, that titanium and zirconium sulfides easily form in copper, mainly in copper melt ${ }^{\dagger}$. The sulfides would form also in the case of additives other than $\mathrm{Ti}, \mathrm{Zr}$ and $\mathrm{V}$. Here, the present authors wish to state that the recrystallization is again enhanced by the addition of boron ${ }^{(5)}$ and IIIa group elements. ${ }^{(8)}$

In relation to the above paragraph, the following experiment was carried out. The ingots of supplementary specimens were annealed at $1073 \mathrm{~K}$ before cold-drawing. The results of Ti-7 and $\mathrm{Zr}-5$ specimens obtained after the annealing-treatment are also shown in Figs. 6 and 7 with the marks of [Ti-7] and [Zr-5], respectively. The rate of recrystallization of these specimens is clearly enhanced by the annealing treatment, approaching the rate of $\mathrm{Cu}$ (3) (refer to Fig. 9). The similar result was obtained for [V-10] specimen. In this case, however, the rate was lower than those of [Ti7] and [Zr-5] specimens, suggesting that the interaction between sulfur and $\mathrm{V}$ was weaker than those between sulfur and $\mathrm{Ti}(\mathrm{Zr})$. In any case, it is emphasized that sulfide formation takes place even in the solid copper.

Taking into account the fact that the solid solubility ${ }^{(10)}$ of sulfur in copper decreases from

$\dagger$ The reasons are as follows: Sulfides were found within the grains of cast structures with a spherical shape, and they have in general extremely high melting points. ${ }^{(20)}$ 


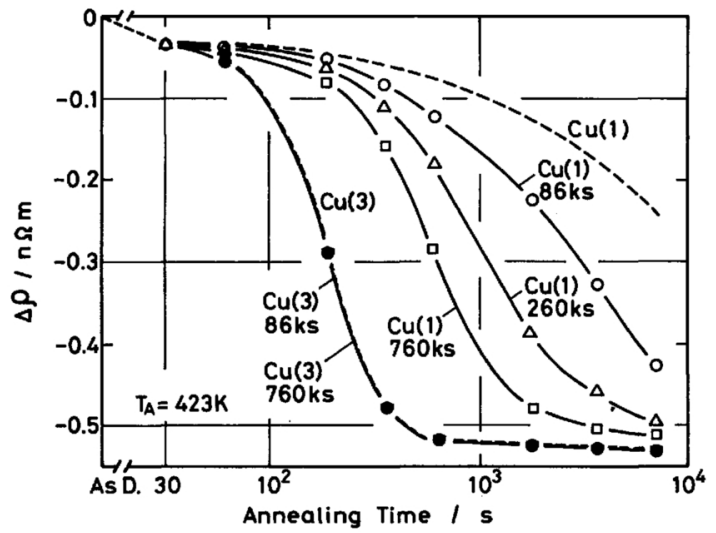

Fig. 13 The $\Delta \rho$ vs. annealing time curves of cold-worked pure coppers. Ingots of $\mathrm{Cu}(1)$ and $\mathrm{Cu}(3)$ were pre-annealed at $773 \mathrm{~K}$ for indicated times before cold-drawing. The curves of $\mathrm{Cu}(1)$ and $\mathrm{Cu}(3)$ are referred to.

$18 \mathrm{~mol} \mathrm{ppm}$ at $1073 \mathrm{~K}$ to $2 \mathrm{~mol} \mathrm{ppm}$ at $873 \mathrm{~K}$, the annealing of ingot at low temperatures prior to cold-working should enhance the recrystallization of cold-worked pure copper. Then, $\mathrm{Cu}(1)$ and $\mathrm{Cu}(3)$ ingots were pre-annealed at $773 \mathrm{~K}$ for times up to $760 \mathrm{ks}$, and then colddrawn to wire. Results obtained for the wire specimens when subjected to isothermal annealing at $423 \mathrm{~K}$ are illustrated in Fig. 13. The rate of recrystallization of $\mathrm{Cu}(1)$ increases to a great extent with increasing pre-annealing time, while that of $\mathrm{Cu}(3)$ is not affected by the pre-annealing. These results show that the recrystallization temperature of commercially available pure copper can be lowered by such a pre-annealing method.

\section{Conclusion}

Annealing characteristics of cold-worked commercially available pure copper with the addition of $\mathrm{Ti}, \mathrm{Zr}, \mathrm{Hf}, \mathrm{V}, \mathrm{Cr}, \mathrm{Mn}$ or $\mathrm{Fe}$ in amounts up to about $1000 \mathrm{~mol} \mathrm{ppm}$ have been studied. The results are summarized as follows:

(1) The trace addition of each element regularly decreased the half-softening temperature $\left(T_{\mathrm{H}}\right)$, that is, it enhanced the recrystallization of cold-worked pure copper. The maximum decrease in $T_{\mathrm{H}}$ was $65-70 \mathrm{~K}$.

(2) Further increase in the addition amount of each additive caused a natural increase in $T_{\mathrm{H}}$, whereas a marked increase in the case of addition of $\mathrm{Zr}$ or $\mathrm{Hf}$ was noted. Cold-worked copper materials having a high heat-resistance and a high electrical conductivity were obtainable by the small addition of merely a $\mathbf{1 7 0}$ mol ppm of $\mathrm{Zr}$ or $\mathrm{Hf}$.

(3) The electrical resistivity of pure copper in the cold-worked state as well as in the annealed state was almost unaffected by a small addition of $\mathrm{Ti}, \mathrm{Zr}$ or $\mathrm{V}$ within several mol ppm. This suggested that the additives interacted with a certain impurity contained in the pure copper and that the interaction related to the enhanced recrystallization. The stored energy of coldworked pure copper was not considered to be influenced by the additives.

(4) The recrystallization of cold-worked pure copper was retarded by increasing sulfur content. The retardation of recrystallization reverted to enhancement by the small addition of $\mathrm{Ti}, \mathrm{Zr}$ or $\mathrm{V}$ to the sulfur-containing specimens. In the specimens with the addition of $\mathrm{Ti}, \mathrm{Zr}$ or $\mathrm{V}$, sulfides of the additives were detected by EDS analyses.

(5) Finally, the enhancement of recrystallization of cold-worked commerically available pure copper due to the addition of transition elements was attributed to the reduction in the impurity of sulfur dissolved in the pure copper, through the sulfide formation of the additives.

(6) In addition, annealing treatment before cold-working was demonstrated to be effective for the reduction of dissolved impurity of sulfur.

\section{REFERENCES}

(1) J. S. Smart: Trans. AIME, 152 (1943), 103.

(2) V. A. Phillips and A. Phillips: J. Inst. Metals, 81 (1952-53), 185.

(3) F. Pawlek and K. Reishel: Z. Metallk., 47 (1956), 347.

(4) S. Hori, H. Tai and H. Katayama: J. Japan Inst. Metals, 45 (1981), 1223 (in Japanese).

(5) H. Suzuki, M. Kanno and T. Maeda: J. Japan Inst. Metals, 47 (1983), 794 (in Japanese).

(6) H. Suzuki, M. Kanno and T. Maeda: J. Japan Inst. Metals, 48 (1984), 209 (in Japanese).

(7) H. Suzuki and M. Kanno: Tetsu-to-Hagané, 70 (1984), 1977 (in Japanese).

(8) H. Suzuki, M. Kanno and T. Ohsako: J. Japan Inst. Metals, 48 (1984), 854 (in Japanese).

(9) M. Hansen and K. Anderko: Constitution of Binary Alloys, McGraw-Hill, New York, (1958).

(10) R. P. Elliott: Constitution of Binary Alloys, First Sup- 
plement, McGraw-Hill, New York, (1964).

(11) H. Suzuki, M. Kanno and I. Kawakatsu: J Japan Inst. Metals, 33 (1969), 628 (in Japanese).

(12) R. Watanabe: J. Japan Inst. Metals, 30 (1966), 754 (in Japanese).

(13) A. Lucci, G. Riontino, M. C. Tabasso, M. Tamanini and G. Venturello: Acta Met., 26 (1978), 615.

(14) F. Haessner, G. Hosheck and G. Tolg: Acta Met., 27 (1979), 1539.

(15) R. O. Williams: Scripta Met., 10 (1976), 661.

(16) D. Coutsouradis, E. Diderrich, J. Smets, G. Croca and L. Pawels: C. R. M., 39 (1974), 73.

(17) L. K. Bigelow and J. H. Chen: Met. Trans., 7B (1976), 661.

(18) J. F. Elliott and G. G. Gleiser: Thermochemistry for Steelmaking, Vol. 1, Amer. Iron and Steel Inst., Addison Wesley, (1960).

(19) E. T. Turkdogen: Physical Chemistry of High Temperature Technology, Academic Press, (1979).

(20) G. V. Samsonov and I. M. Vinitski: Handbook of Refractory Compounds, IFI/Plenum, New YorkWashington-London, (1980). 